- A new alternative interocclusal recording method using impression material reinforced by a stabilising tray has been compared to conventional methods in three clinical cases.

- There were no significant differences between the methods because clinical factors and clinical variation rather than recording materials or mandibular positions determined the range of the positions of the mounted casts.

- The new interocclusal recording method ie a combination of impression material/stabilising tray in most cases can replace record rims and the number of appointments therefore can be reduced.

\title{
Clinical factors and clinical variation influencing the reproducibility of interocclusal recording methods
}

\author{
A. Eriksson, ${ }^{1}$ G. Öckert-Eriksson, ${ }^{2}$ P. Lockowandt ${ }^{3}$ and O. Eriksson ${ }^{4}$
}

Objective The reproducibility of clinical records of the occlusion was assessed in three dimensions using mounted casts. Three distinct areas were examined: 1) mandibular positions (intercuspal position (IP) or retruded contact position $(\mathrm{RCP})), 2$ ) materials used in recording the occlusion, 3) clinical variation.

Design Interocclusal records were made in a random order of three patients: one fixed prosthodontics case, one removable partial denture case and one complete denture case, with two different types of waxes, record rims, two different brands of vinyl polysiloxanes and one irreversible hydrocolloid.

Setting Private practice and Karolinska Institute, Huddinge, Sweden. Subjects One general dental practitioner and three voluntary patients. Results Point estimation of variance components indicate that 70-93\% of the variation of the positions of the mounted casts are caused by: 1) clinical variation for all three cases and in three directions, 2) the influence of recording materials 0-29\%, and 3) mandibular positions (IP/RCP) $0-11 \%$. The ranges of the positions of the mounted casts were lower for the dentate case $(0.04-1.39 \mathrm{~mm})$ than for the partially dentate case $(0.17-2.65 \mathrm{~mm})$, which in turn was lower than those for the edentulous case (1.42-5.59 mm).

Conclusion Clinical variation seems to dominate the variation in positions of mounting casts when making interocclusal records, rather than mandibular position or the recording materials used. Therefore a dentist who makes one single interocclusal record cannot presume that it will reproduce the interocclusal relationship intended, which in the present study was most obvious for the edentulous case. The results showed that impression materials stabilised by a tray did not differ significantly from waxes and record rims concerning the reproducibility. Therefore the stabilised impression materials are an alternative, which also give additional advantages like reduction of appointments as well as superior accuracy.

${ }^{1}$ Research Assistant, General Dental Practitioner, Department of Dental Biomaterial Science, Karolinska Institute, Huddinge, and Murgatan 3, 59621 Skänninge, Sweden, ${ }^{2}$ Research Assistant, Department of Dental Biomaterial Science, Karolinska Institute Huddinge, Sweden, ${ }^{3}$ Professor emeritus, Department of Dental Biomaterial Science, Karolinska Institute Huddinge, Sweden, ${ }^{4}$ Instructor, Department of Mathematics, University of Linköping, Sweden

*Correspondence to: A. Eriksson P.0. Box 4, S-596 21 Skänninge, Sweden

E-mail:anderik@swipnet.se

\section{Refereed paper}

Received 27.11.00; Accepted 16.10.01

๑ British Dental Journal 2002; 192: 395-400
Restorative procedures that require the mounting of casts on articulators need accurate interocclusal registrations. For opposing casts to be held together in a stable and reproducible manner, both a tripod for vertical support and a satisfactory horizontal stability between the two casts are required. ${ }^{1}$ There are in principle two methods of measuring accuracy in 3-dimensions of mounted casts: 1) the indirect way, ${ }^{2}$ where movements of the condyles are measured with a condymeter system, which allows calculation of positions of the casts on the articulator; 2) the direct way, ${ }^{3}$ where reference points are placed on the measuring casts and their actual positions can be registered.

For the technician it is important that the casts can be mounted on the articulator in such a way that the relationship between the casts corresponds to the jaw relationship in the patient's mouth in lateral, anteroposterior and vertical dimensions. According to Warren and Capp, ${ }^{4}$ the basic principal approach should be to make the interocclusal record at the correct occlusal vertical dimension, choosing an accurate, dimensionally stable recording material, and selecting an appropriate method of mandibular guidance. It is, however, difficult for the clinician to judge whether one singular interocclusal record will reproduce the 3dimensional mandible position intended. Many factors influence the accuracy of an interocclusal record, eg the materials used, ${ }^{5}$ the positions of the condyles, intercuspal position (IP) or retruded contact position (RCP), and other clinical variations which are involved in the recording procedure. ${ }^{6}$ Reproducibility means that the relation of the mandible to the maxillae can be reproduced time after time with very little variation. ${ }^{6}$ Therefore, possible deviations should never exceed variation due to the measuring device, unless choice of material, mandibular position or additional clinical variation would influence the accuracy of the interocclusal records. Helkimo et al. ${ }^{6}$ have estimated the range of clinical variation to be $0.11 \mathrm{~mm}$ laterally and $0.07 \mathrm{~mm}$ anteroposteriorally, and $\mathrm{McKee}^{7}$ has suggested a tolerance within $0.11 \mathrm{~mm}$ of achieving centric relation by measuring for dentate patients' condylar movements in the articulator. Watson et al. ${ }^{8}$ found by measuring actual positions of mounted casts, that for edentulous patients the interclinical (five separate clinicians' recordings) lateral range was $0.95-3.5 \mathrm{~mm}$, anteroposterior range $1.85-4.12$ $\mathrm{mm}$, and vertical range $1.67-5.87 \mathrm{~mm}$ and the intraclinical range (five recordings from each clinician) was $0.56-2.38 \mathrm{~mm}, 1.1-2.21$ $\mathrm{mm}$, and 2.02-5.68 $\mathrm{mm}$ respectively. 


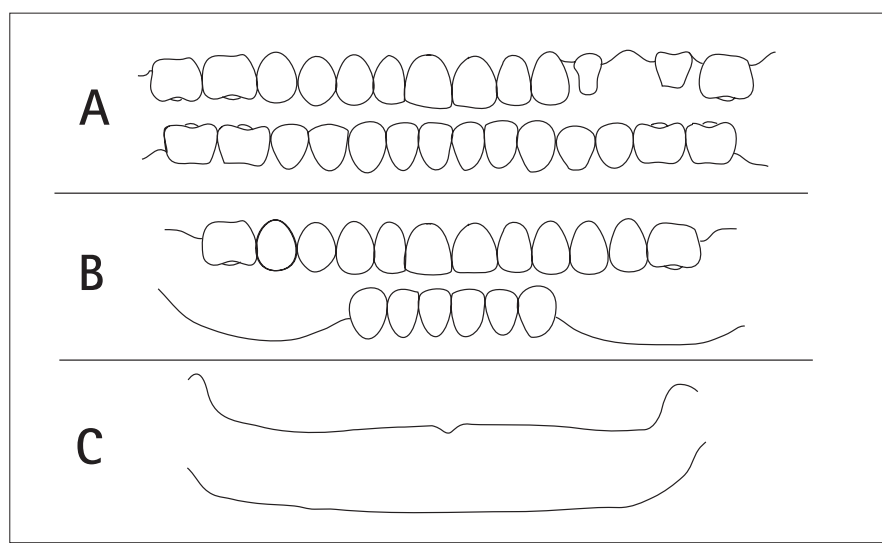

Fig 1. (A) Fixed prosthodontics, (B) removable partial and (C) complete denture cases.

Waxes and vinyl polysiloxanes are today the most commonly used recording materials. Posselt ${ }^{9}$ thought that irreversible hydrocolloid (alginate) records were superior to wax, but shrinkage made them useless after a few minutes. Irreversible hydrocolloids, used as occlusal records, are stable enough after 6 days. ${ }^{5}$ They can also provide a detailed reproduction of $20 \mu \mathrm{m}^{10}$ and have sufficient dimensional stability if correctly handled and stored. ${ }^{11}$ Therefore, an irreversible hydrocolloid used as interocclusal recording material was included in the present study to test whether its accuracy is comparable with that of vinyl polysiloxanes, waxes, or record rims.

The authors have designed a stabilising tray and invented a method that always makes immediate interocclusal recording possible for removable partial or complete dentures as well, without using record rims. An interocclusal record has impressions of the upper jaw on one side and of the lower jaw on the other. Therefore it can also be defined as a 'jaw relationship impression'. Such an impression should have three parts: a fixing, a stabilising and a guiding part in order to secure the mounting of the working casts. The fixing part should be an impression material which can reproduce both the hard and soft tissues distinctly and after setting have sufficient rigidity so the casts can be correctly placed and fixed. The stabilising part reinforces the impression material when it is placed in the patient's mouth and after setting, during transport and trimming (cp. Posselt-plate). The guiding part helps to orient the interocclusal record to an anatomic horizontal plane, eg the handle of the stabilising tray. The vinyl polysiloxanes and irreversible hydrocolloids are able to reproduce both the hard and soft tissues, while waxes have a poor ability and the base plates of a record rim a very poor ability. ${ }^{5}$

The aim of this study was to:

- Examine the 3-dimensional reproducibility of mounting casts by letting one clinician (30 years experience), make randomly repeated interocclusal records of three patients: one fixed prosthodontics case, one removable partial denture case and one complete denture case.

- Compare the reproducibility of conventional recording materials, ie waxes and record rims, with impression materials stabilised by a tray.

- Estimate, by using variance components, how three areas: 1) mandibular positions (intercuspal position (IP) or retruded contact position (RCP)), 2) materials used and 3) clinical variation influenced the precision regarding reproducibility, when mounting casts.

\section{METHODS AND MATERIALS}

Three patients: one dentate, one partially edentulous and one edentulous as shown in Figure 1 participated in this study. Their ages were $51(\mathrm{~F}), 55(\mathrm{M})$ and $68(\mathrm{M})$ years respectively. When recording the occlusion, the patients were seated in the upright position (60 degrees from the horizontal plane). The order of recording materials and mandibular positions was randomised.

Two different types of waxes, record rims, two brands of vinyl polysiloxanes, and one irreversible hydrocolloid were examined (Table 1). All materials were manipulated according to the manufacturers instructions except for the irreversible hydrocolloid which was mixed with $18 \mathrm{ml}$ water to make it more rigid, instead of the recommended $23 \mathrm{ml}$ per $10 \mathrm{~g}$ powder.

\section{Mandibular positions}

The IP position in the dentate and partially dentate subjects was determined by asking the patients to close their mouth in a relaxed way into a position with the most complete interdigitation of opposing teeth independent of condylar position. The complete denture patient was asked to hum 'mmm' in a position where the vertical dimension was perceived as comfortable for the patient and was then measured with a calliper. The RCP position in the dentate subject was determined with a one hand chin point guidance technique into the most retruded contact position. The vertical dimensions for the partial removable and complete denture patients were measured with a calliper after the mandible was guided into the most retruded position.

\section{Measuring casts}

One pair of measuring casts were made of Prima Rock type IV gypsum (setting expansion $0.13 \%$; Whip Mix) for each patient and three measuring steel rods were attached to each measuring cast as shown in Figures 2, 3 and 4.

\section{Articulator and measuring device}

An adjustable articulator (Dentatus, type ARD) was used for all mountings which were made with Modell Gips (Hilliges Gipswerk). The condylar mechanism was locked in one position during the testing period, ie the maxillary member of the articulator could be opened by a pure rotational hinge movement only. ${ }^{6}$ The

Table 1 Recording materials and type I gypsum used in this study.

\begin{tabular}{lllll}
\hline Product & Type & Setting time & Manufacturer & Batch \\
\hline Alminax wax & Metal-wax comp. & Ass. Dental Prod., Swindon, UK & 219262 \\
Record rims (wax) & Thermoplastic wax & & Metrodent, Huddersfield, UK & $517-98$ \\
Record rims (base plates) & Individual trays & & Cavex, Haarlem, Holland & 970210 \\
Blu Mousse Super Fast & Poly vinylsiloxane & $45 \mathrm{~s}^{*}$ & Parkell, Farmingdale, NY, USA & $7223-223$ \\
Green Rapid DF & Irr. hy-co & $2 \mathrm{~min}^{*}$ & Svedia Dental, Enköping, Sweden & 029704 \\
Momax (base, catalyst) & ZOE paste & $2.5 \mathrm{~min}^{*}$ & Svedia Dental, Enköping, Sweden & 9705 \\
Silagum AV-Putty, st. & Poly vinylsiloxane & $5.5 \mathrm{~min}^{*}$ & DMG, Hamburg, Germany & 98080108 \\
Tenax wax & Thermoplastic wax & & S.S. White, Gloucester, UK & 459751 \\
Modell Gips & Mounting plaster & 4 min & Hilliges Gipswerk, Osterode, Ger. & $91 / 155$ \\
\hline
\end{tabular}

${ }^{*}=$ from start of mixing at $23^{\circ} \mathrm{C}$, higher temperature shortens, lower temperature prolongs setting times 


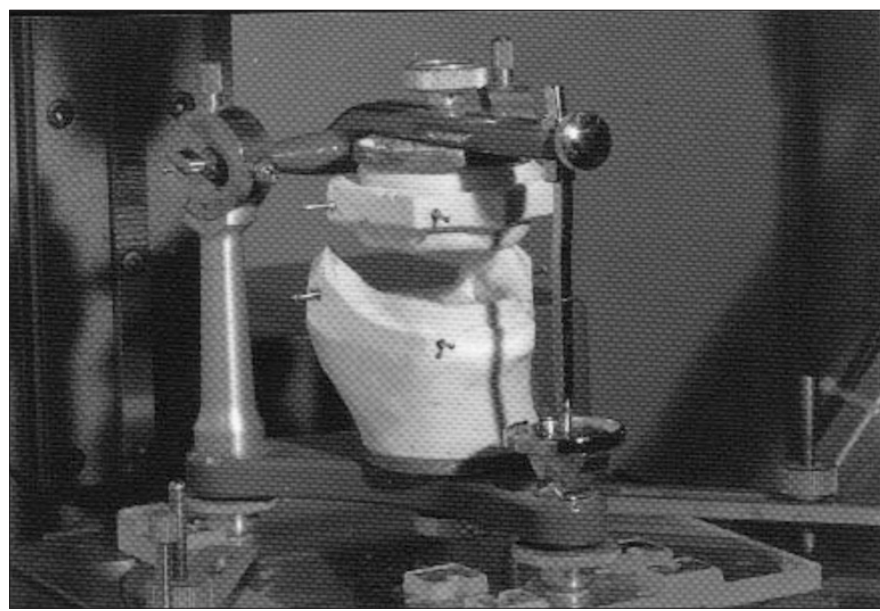

Fig 2. Placement of 3 pairs of measuring rods. Master casts of the complete denture case mounted on the articulator in an upright position and placed on the jig.

articulator could be placed in two perpendicular positions on an acrylic glass jig, where the $\mathrm{x}$ - and $\mathrm{y}$-distances between the measuring rods were measured in one position and the z-distances in the other, which is shown in Figures 3 and 4. The jig was positioned on the horizontally movable table of a $10 \mathrm{x}$ measuring microscope (UWM Leitz) and was connected to a display (Heidenhain), where the distances between the rods were measured in lateral (x), anteroposterior $(\mathrm{y})$ and vertical $(\mathrm{z})$ directions with a reading precision of $1 \mu \mathrm{m}$. The range of the measuring error was 0.04 $\mathrm{mm}$ (10 repeated measurements on one set of casts).

\section{Interocclusal records}

Five interocclusal records were made of each technique-materialposition combination and their application can be seen in Tables 1 and 2. Stabilising trays shown in Figure 5 were designed by the authors, and were used to reinforce the recording material before and after its setting and helped to carry it into position. The trays were made of aluminium and had three different shapes. Tray 1 was used for fixed prosthodontics, tray 2 for removable partial, and tray 3 for complete denture cases as shown in Figure 6.

Records of waxes and vinyl polysiloxanes were stored in open air, and irreversible hydrocolloid records were stored in plastic bags $\left(95 \% \pm 5 \%\right.$ humidity, $\left.21 \pm 1^{\circ} \mathrm{C}\right)$. All records were stored for three days before mounting.

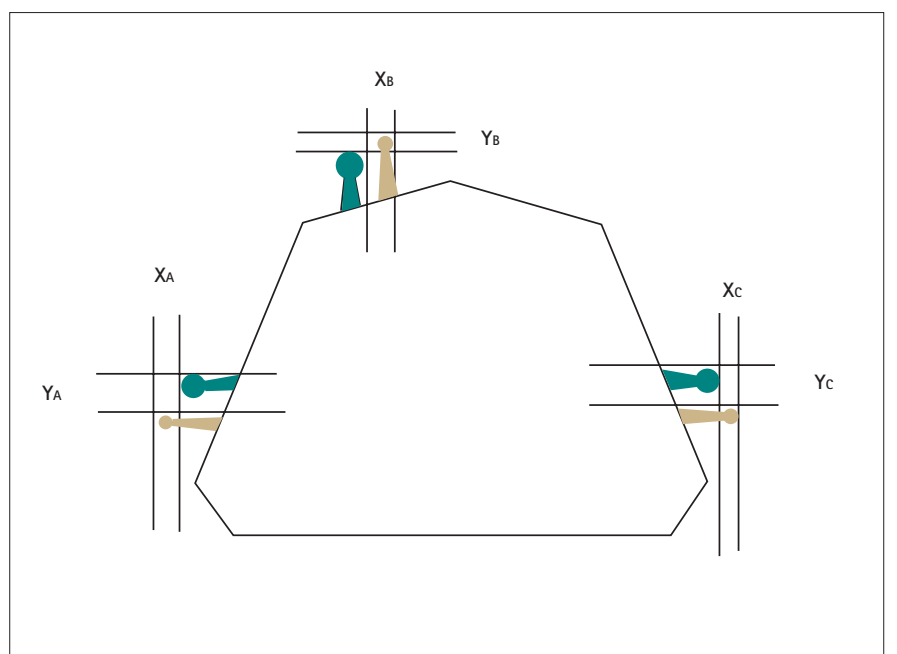

Fig 3. One pair of master casts seen from above. $X A, X B$, and $X C=$ lateral distances between the measuring rods; $Y A, Y B$, and $Y C=$ anteroposterior distances between the measuring rods.
Table 2 Applications for the different interocclusal recording materials

\begin{tabular}{lccc}
\hline Material & Dentate case & Partially dentate case & Edentulous case \\
\hline Alminax wax & $\mathrm{x}$ & & \\
Bite Blocks +(Momax) & & $\mathrm{x}$ & $\mathrm{x}$ \\
Blu Mousse Super Fast & $\mathrm{x}$ & $\mathrm{x}$ & \\
Green Rapid DF & $\mathrm{x}$ & $\mathrm{x}$ & $\mathrm{x}$ \\
Silagum AV-Putty, standard & & $\mathrm{x}$ & $\mathrm{x}$ \\
Tenax wax & $\mathrm{x}$ & $\mathrm{x}$ & \\
\hline
\end{tabular}

Storage times for the testing materials were 3 days before mounting the maxillary cast on the articulator.

\section{Fixed prosthodontics case.}

Waxes were prepared in a water bath $\left(45 \pm 2^{\circ} \mathrm{C}\right)$ for 5 minutes before making records. Blu Mousse was applied in three ways: 1) direct syringing on occlusal surfaces of the mandible using a mixing dispenser, or 2) using tray 1 (T1) to carry it into position, or 3) by guiding the patient to close into the desired mandibular position and then syringing the interocclusal recording material buccally and then immediately place the stabilising tray 1 into the material (T1 syr). Green Rapid was applied in two ways according to 2) and 3) above except for the syringe, which was exchanged for a Monoject 412 (Sherwood Medical).

\section{Removable partial denture case.}

Mandibular record rims made of base plates and wax were trimmed in such a way that $1 \mathrm{~mm}$ of space from the maxilla was formed. To fill that space, Momax was placed onto the record rims to get a detailed impression of the maxilla when positioned in the occlusion. Green Rapid and Silagum were applied using tray 2 only.

\section{Complete denture case.}

Record rims, Silagum, and Green Rapid, were handled in a way similar to the partial removable denture case, but tray 3 was used, see Figures 5 and 6 . For the edentulous case, the vertical dimension was measured with a calliper.

\section{Mounting on the articulator}

The mandibular cast from each patient was first mounted on the articulator, and was never removed during the test period. The maxillary casts were mounted three days after record making in the following way. The occlusal record was trimmed and placed on the mandibular cast. The maxillary cast was then positioned on the record and manually fixed during the two minutes initial setting of

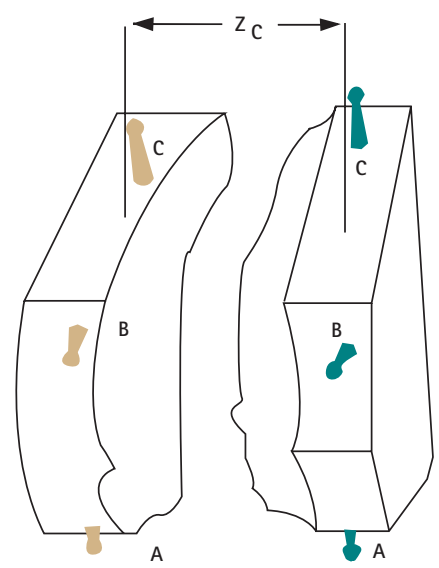

Fig 4. Complete denture casts. $\mathrm{ZC}=$ vertical distance between the measuring rods. 
Table 3 Estimated influence on variations in position of mounted casts of 3 variance components (mandibular positions, materials used and clinical variation) for fixed prosthodontics, removable partial denture and complete denture cases

\begin{tabular}{|c|c|c|c|c|c|c|c|}
\hline & & \multicolumn{2}{|c|}{ Fixed Prost. case } & \multicolumn{2}{|c|}{$\underline{\text { RPD case }}$} & \multicolumn{2}{|c|}{ Compl. Dent. case } \\
\hline & & Variance & $\%$ & Variance & $\%$ & Variance & $\%$ \\
\hline \multirow[t]{4}{*}{ Lateral } & IP/RCP & 0.0000 & 0 & 0.0000 & 0 & 0.0187 & 11 \\
\hline & M & 0.0034 & 29 & 0.0010 & 15 & 0.0000 & 0 \\
\hline & CV & 0.0082 & 71 & 0.0057 & 85 & 0.1458 & 89 \\
\hline & Total & 0.0116 & 100 & 0.0067 & 100 & 0.1645 & 100 \\
\hline \multirow[t]{4}{*}{ Anteroposterior } & $\mathrm{IP} / \mathrm{RCP}$ & 0.0019 & $2^{*}$ & 0.0109 & 7 & 0.0728 & 8 \\
\hline & M & 0.0342 & $32^{*}$ & 0.0243 & 15 & 0.2046 & 22 \\
\hline & CV & 0.0717 & $66^{*}$ & 0.1261 & 78 & 0.6514 & 70 \\
\hline & Total & 0.1078 & 100 & 0.1613 & 100 & 0.9288 & 100 \\
\hline \multirow[t]{4}{*}{ Vertical } & IP/RCP & 0.0005 & 3 & 0.0054 & 4 & 0.0000 & 0 \\
\hline & M & 0.0027 & 18 & 0.0326 & 23 & 0.1103 & 9 \\
\hline & CV & 0.0123 & 79 & 0.1040 & 73 & 1.1367 & 91 \\
\hline & Total & 0.0155 & 100 & 0.1420 & 100 & 1.2470 & 100 \\
\hline
\end{tabular}

$\mathrm{M}=$ Materials, IP/RCP = Mandibular Position, $\mathrm{CV}=$ Clinical variation

${ }^{*}=$ in this case, significant interaction was present, and therefore the estimation of variance components may not be valid.

the mounting gypsum (water:powder ratio $12 \mathrm{ml}: 24 \mathrm{~g}$, mixing time 20 seconds). The record was immediately removed after setting (4 minutes), and the upper member of the articulator was closed until the measuring casts came into contact. Concerning the edentulous casts, the occlusal vertical dimension was determined by the incisal pin, which was not moved during the testing period. The upper member of the articulator was then fixed in a closed position with rubber bands, and the articulator was placed on the measuring device.

\section{Statistical analysis}

Two way balanced analysis of variance with fixed factor levels without interaction was used to determine the relative contribution of materials, mandibular position, and clinical variation to the overall variability of the occlusal records. ${ }^{12}$

\section{RESULTS}

When the influence of variations in position of the mounted casts was estimated for the three areas studied, the clinical variation dominated in all three directions in all cases, rather than mandibu-

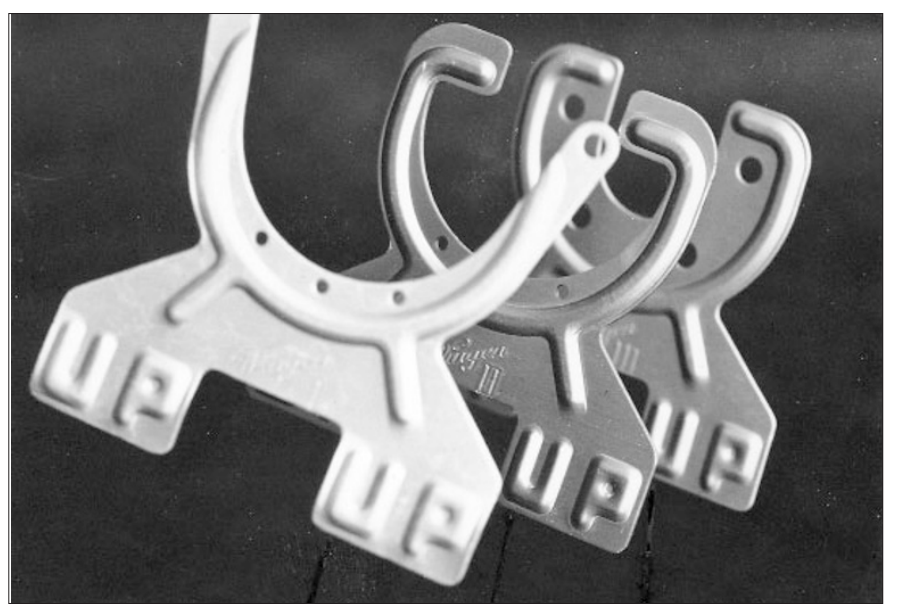

Fig 5. (left) tray 1 (for dentate patients), (centre) tray 2 (for partially dentate patients), and (right) tray 3 (for patients who are edentulous in one or both jaws). lar positions or materials used, as seen in Table 3. The results for the three areas were: 1) laterally, a rate of $71-89 \%$, where the clinical variation was estimated to have the lowest influence on the fixed prosthodontics case and highest on the complete denture case; 2) anteroposteriorally $66-78 \%$ where the clinical variation was estimated at have the lowest influence on the fixed prosthodontics case and highest on the removable partial denture case; 3) vertically 73-91\%, with the lowest estimated influence on the removable partial denture case and highest on the complete denture case.

The influence of variations in position in lateral direction due to mandibular positions IP/RCP was estimated to be $0 \%$ except for the complete denture case (11\%); anteroposteriorally, it was estimated to $2-8 \%$, where the mandibular positions had the lowest influence on the fixed prosthodontics case and the highest on the complete denture case. Vertically, the mandibular positions was estimated to have little influence (0-4\%).

The influence of variations in position in lateral direction due to materials used was estimated to be $0-29 \%$, the fixed prosthodontics case $29 \%$, the removable partial denture case $15 \%$ and the complete denture case $0 \%$. Anteroposteriorally, it was estimated to be $15-32 \%$ with the highest influence on the fixed prosthodontics case and lowest on the removable partial denture case. Vertically, it was estimated to be $9-23 \%$, where the fixed prosthodontics case was estimated to be $18 \%$, the removable partial denture case $23 \%$ and the complete denture case $9 \%$.

\section{Interocclusal records for the fixed prosthodontics case}

These produced variations in position of the mounted casts as presented in Table 4. None of the tested mandibular position/ material combinations produced mean values that differed significantly from each other taking all three directions into consideration.

Regarding the ranges of the five mountings, only mountings without an interocclusal record produced intervals within those mentioned, (laterally 0.11 , anteroposteriorally 0.07 and vertically $0.04 \mathrm{~mm}$ ie measuring error $0.04 \mathrm{~mm}$ ). Green Rapid (T1 syr) made in IP produced an interval of $0.04 \mathrm{~mm}$ in vertical direction. Blu Mousse (T1 syr) made in IP produced an interval of $0.08 \mathrm{~mm}$ in lateral direction, and $0.07 \mathrm{~mm}$ in anteroposterior directions.

\section{Interocclusal records for the removable partial denture case}

These produced variation in the position of the mounted casts as presented in Table 5. None of the tested mandibular position/ material combinations produced mean values that differed significantly from each other, taking all three directions into consideration.

None of the tested materials produced ranges within similar intervals as given for the fixed prosthodontics case.

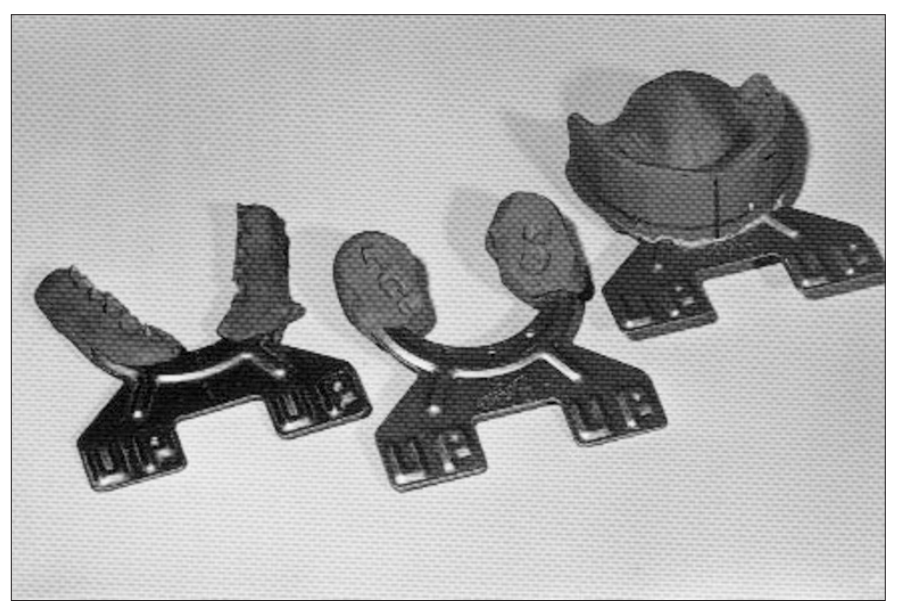

Fig 6. Trimmed interocclusal records stabilized by (left) tray 1 (fixed prosthodontics case ), (centre) tray 2 (removable partial denture case), and (right) tray 3 (complete denture case). 
Table 4 Mean values and ranges of the actual distances between the measuring rods in 3 directions depending on different interocclusal record materials and mandibular positions for the fixed prosthodontics case $(\mathrm{mm})$

\begin{tabular}{|c|c|c|c|c|c|c|c|c|c|c|c|c|}
\hline \multirow[b]{3}{*}{ Materials } & \multicolumn{4}{|c|}{ Lateral } & \multicolumn{4}{|c|}{ Anteroposterior } & \multicolumn{4}{|c|}{ Vertical } \\
\hline & \multicolumn{2}{|c|}{ Distance } & \multicolumn{2}{|c|}{ Range } & \multicolumn{2}{|c|}{ Distance } & \multicolumn{2}{|c|}{ Range } & \multicolumn{2}{|c|}{ Distance } & \multicolumn{2}{|c|}{ Range } \\
\hline & IP & $\mathrm{RCP}$ & IP & $\mathrm{RCP}$ & IP & $\mathrm{RCP}$ & IP & $\mathrm{RCP}$ & IP & $\mathrm{RCP}$ & IP & $\mathrm{RCP}$ \\
\hline Alminax wax & 0.46 & 0.32 & 0.42 & 0.20 & 3.74 & 4.39 & 1.11 & 0.49 & 8.57 & 8.41 & 0.75 & 0.51 \\
\hline Blu Mousse & 0.32 & 0.28 & 0.25 & 0.17 & 4.52 & 4.51 & 0.30 & 0.33 & 8.33 & 8.39 & 0.51 & 0.45 \\
\hline Blu Mousse + T1 & 0.38 & 0.37 & 0.24 & 0.25 & 4.37 & 4.57 & 0.59 & 0.46 & 8.45 & 8.33 & 0.51 & 0.27 \\
\hline Blu Mousse + T1 syr & 0.17 & 0.17 & 0.08 & 0.10 & 4.32 & 4.30 & 0.07 & 0.24 & 8.54 & 8.55 & 0.23 & 0.27 \\
\hline Green Rapid + T1 & 0.20 & 0.25 & 0.41 & 0.66 & 4.25 & 3.90 & 0.48 & 1.39 & 8.48 & 8.49 & 0.65 & 0.91 \\
\hline Green Rapid + T1 syr & 0.25 & 0.30 & 0.16 & 0.17 & 4.40 & 4.33 & 0.12 & 0.32 & 8.48 & 8.46 & 0.04 & 0.34 \\
\hline Tenax wax & 0.27 & 0.30 & 0.14 & 0.19 & 4.22 & 4.39 & 0.63 & 0.31 & 8.51 & 8.47 & 0.41 & 0.33 \\
\hline Without record & 0.26 & & 0.11 & & 4.41 & & 0.04 & & 8.47 & & 0.03 & \\
\hline Max. - min. & 0.29 & 0.20 & & & 0.78 & 0.67 & & 0.24 & 0.22 & & & \\
\hline Pooled SD & & & & & & & & & & & & \\
\hline
\end{tabular}

$n=5$, ie 5 interocclusal records were made of each material/mandibular position combination. $T 1$ = stabilising tray 1 , syr $=$ the interocclusal material was syringed buccally.

Table 5 Mean values and ranges of the actual distances between the measuring rods in 3 directions depending on different interocclusal record materials and mandibular positions for the removable partial denture case $(\mathrm{mm})$

\begin{tabular}{|c|c|c|c|c|c|c|c|c|c|c|c|c|}
\hline \multirow[b]{3}{*}{ Materials } & \multicolumn{4}{|c|}{ Lateral } & \multicolumn{4}{|c|}{ Anteroposterior } & \multicolumn{4}{|c|}{ Vertical } \\
\hline & \multicolumn{2}{|c|}{ Distance } & \multicolumn{2}{|c|}{ Range } & \multicolumn{2}{|c|}{ Distance } & \multicolumn{2}{|c|}{ Range } & \multicolumn{2}{|c|}{ Distance } & \multicolumn{2}{|c|}{ Range } \\
\hline & IP & $\mathrm{RCP}$ & IP & $\mathrm{RCP}$ & IP & $\mathrm{RCP}$ & IP & $\mathrm{RCP}$ & IP & $\mathrm{RCP}$ & IP & $\mathrm{RCP}$ \\
\hline Blu Mousse $+\mathrm{T} 2$ & 0.09 & 0.09 & 0.17 & 0.25 & 3.92 & 4.00 & 0.46 & 0.64 & 4.02 & 3.92 & 0.70 & 0.50 \\
\hline Blu Mousse + T1 syr & 0.14 & 0.09 & 0.58 & 0.27 & 4.09 & 4.41 & 0.61 & 0.64 & 3.75 & 3.77 & 1.22 & 0.73 \\
\hline Green Rapid + T2 & 0.02 & 0.08 & 0.17 & 0.25 & 3.96 & 4.07 & 0.23 & 0.23 & 3.94 & 3.91 & 0.53 & 0.55 \\
\hline Green Rapid + T1 syr & 0.13 & 0.14 & 0.47 & 0.32 & 3.79 & 4.32 & 1.11 & 0.48 & 4.09 & 3.77 & 1.69 & 0.37 \\
\hline Record Rims + Momax & 0.06 & 0.08 & 0.25 & 0.33 & 4.01 & 4.27 & 0.67 & 0.88 & 4.62 & 4.18 & 0.60 & 0.87 \\
\hline Silagum + T2 & 0.07 & 0.05 & 0.29 & 0.18 & 3.85 & 3.97 & 1.13 & 0.43 & 4.12 & 3.94 & 1.06 & 0.44 \\
\hline Tenax wax + T2 & 0.21 & 0.11 & 0.52 & 0.55 & 3.54 & 3.68 & 1.92 & 1.40 & 4.33 & 4.21 & 2.65 & 1.65 \\
\hline Max-min & 0.19 & 0.09 & & & 0.55 & 0.64 & & & 0.87 & 0.44 & & \\
\hline Pooled SD & & & & & & & & & & & & \\
\hline
\end{tabular}

$n=5$, ie 5 interocclusal records were made of each material/mandibular position combination. $T 1=$ stabilising tray 1 , syr $=$ the interocclusal material was syringed buccally. $T 2=$ stabilising tray 2 .

Table 6 Mean values and ranges of the actual distances between the measuring rods in 3 directions depending on different interocclusal record materials and mandibular positions for the complete denture case $(\mathrm{mm})$

\begin{tabular}{|c|c|c|c|c|c|c|c|c|c|c|c|c|}
\hline \multirow[b]{3}{*}{ Materials } & \multicolumn{4}{|c|}{ Lateral } & \multicolumn{4}{|c|}{ Anteroposterior } & \multicolumn{4}{|c|}{ Vertical } \\
\hline & \multicolumn{2}{|c|}{ Distance } & \multicolumn{2}{|c|}{ Range } & \multicolumn{2}{|c|}{ Distance } & \multicolumn{2}{|c|}{ Range } & \multicolumn{2}{|c|}{ Distance } & \multicolumn{2}{|c|}{ Range } \\
\hline & IP & $\mathrm{RCP}$ & IP & $\mathrm{RCP}$ & IP & RCP & IP & $\mathrm{RCP}$ & IP & $\mathrm{RCP}$ & IP & $\mathrm{RCP}$ \\
\hline Green Rapid + T3 & 0.47 & 0.80 & 1.62 & 2.15 & 1.93 & 1.54 & 2.15 & 3.12 & 15.75 & 14.78 & 2.68 & 3.30 \\
\hline Record Rims + Momax & $<0.55$ & 0.90 & 1.83 & 2.27 & 1.02 & 0.24 & 2.70 & 2.45 & 14.05 & 14.41 & 5.59 & 3.46 \\
\hline Silagum + T3 & 0.47 & 0.71 & 1.61 & 1.42 & 1.97 & 1.29 & 2.83 & 3.11 & 15.04 & 14.85 & 3.61 & 3.99 \\
\hline Max. - min. & 0.08 & 0.19 & & & 0.95 & 1.30 & & & 1.70 & 0.44 & & \\
\hline Pooled SD & & & & & & & & & 1. & & & \\
\hline
\end{tabular}

$n=5$, ie 5 interocclusal records were made of each material/mandibular position combination. $T 3=$ stabilising tray 3.

\section{Interocclusal records for the complete denture case}

These produced variations in position of the mounted casts as presented in Table 6 . None of the tested mandibular position/material combinations produced mean values that differed significantly from each other, taking all 3 directions into consideration.

Regarding the ranges, only Green Rapid (IP) produced intervals within the given limits: lateral $2.38 \mathrm{~mm}$, anteroposterior $2.21 \mathrm{~mm}$ and vertical $5.68 \mathrm{~mm}$. All position/material combinations produced intervals less than $2.55 \mathrm{~mm}$ in lateral direction. Silagum (IP), Green Rapid (RCP) and record rims (RCP) produced intervals less than $3.66 \mathrm{~mm}$ in vertical direction.

When calculating the difference between the IP and RCP positions in lateral direction there was a significant deviation to the right for the complete denture case. In anteroposterior directions, the RCP positions were significantly more posterior than the IP positions, both for the removable partial and the complete denture cases.

The ranges in position of the mounted casts throughout the present results were lower for the dentate case (0.04-1.39 $\mathrm{mm})$ than for the partially dentate case $(0.17-2.65 \mathrm{~mm})$, which in turn was lower than those for the edentulous case (1.42-5.59 $\mathrm{mm}$ ) as shown in Tables 4, 5 and 6 .

When estimating the variance of the clinical variation separately for interocclusal records stabilised by a tray and interocclusal records made without a stabilising tray, the latter variance was not significantly lower in any direction or case. 


\section{DISCUSSION}

The study shows the expected results, namely that mandibular positions have little or no influence on positions of mounted casts in lateral or vertical directions, but also very little influence anteroposteriorally, which was not expected.

The present study reflects the daily situation in a dental clinic, where one dentist makes all interocclusal records. The authors therefore have chosen to let only one operator participate. Since Watson et al. ${ }^{8}$ showed that the intra-clinician range was somewhat lower than that of the inter-clinician range, when recording the occlusion for complete denture cases, a conclusion might be that additional operators in this study would have produced similar results but probably with larger ranges. The clinical variation appeared to detrimentally affect the precision of reproducibility. Therefore, these uncontrollable variations need to be analysed in order to find standardised methods to minimise them.

The reason for achieving reproducibility is a wish that repeated interocclusal registrations should produce mounting of casts on the articulator without variation of positions. Therefore limits ought to be present which embrace a certain range of variation in cases which require reproducibility. According to the present results, the possibility that five mountings would produce exact concordance in three dimensions is negligible, and therefore it is questionable whether reproducibility can be achieved. Regarding the fixed prosthodontics case, only one set of five mountings gave deviations less than $0.11 \mathrm{~mm}$ laterally, $0.07 \mathrm{~mm}$ anteroposteriorally and $0.04 \mathrm{~mm}$ vertically, namely when no interocclusal records were used. These facts support Freilich's ${ }^{1}$ opinion that interocclusal records are unnecessary in many cases. The vertical deviation of $0.04 \mathrm{~mm}$ also corresponds to the tactile threshold of perceived thickness described by Mericske-Stern. ${ }^{13}$ Breeding et al. ${ }^{14}$ also found that mounting casts with a one-tooth interocclusal record, will generate a deviation of approximately $0.05 \mathrm{~mm}$. Impression materials, eg Blu Mousse or Green Rapid, when syringed onto the buccal surfaces after closure in any mandibular position and stabilised by tray 1 , also gave mountings close to the range limits compared with waxes.

Concerning the removable partial denture case, none of the interocclusal records were able to repeat mountings with a similar precision, probably due to the poorer horizontal and vertical support. Green Rapid stabilised by tray 2 gave the lowest ranges and Tenax wax stabilised by tray 2 gave the highest, ie the method of just warming a great lump of wax, is not to be recommended.

Concerning the complete denture case, Green Rapid stabilised by tray 3 , made in IP position, gave the lowest range in all three directions. According to Öckert-Eriksson, ${ }^{5}$ record rims gave the largest variation, also in a laboratory test. The unexpected lateral deviation due to mandibular position (Table 3) might depend on condylar anatomic defects. Larger variation limits ought to be accepted for reproducibility of partially dentate and edentulous cases compared to fixed prosthodontics cases.
Helkimo ${ }^{6}$ states that it is difficult to control the patient's state of relaxation and to what extent the patient has understood the dentist's instructions. Body, head and tongue position, state of residual ridges, general health, TMJ pathology, anaesthesia and medication, attitude and co-operation are also factors difficult to control, grade or measure. Helkimo listed nine groups of factors: recording device and methods, recording medium, recording technique, pressure on the mandible, neuromuscular conditioning, measuring technique operator factors, handling of the records after recording and patient factors (total 83), which can influence the reproducibility of a jaw relationship. The large number of factors explain why the clinical variation had a negative influence on reproducibility, compared to the influences of mandibular positions or materials used.

\section{CONCLUSION}

Clinical variation seems to dominate the variation in positions of mounting casts when making interocclusal records. Therefore a dentist who makes one single interocclusal record cannot presume that it will reproduce the interocclusal relationship intended, which in the present study was most obvious for the edentulous case. Concerning the reproducibility the results showed that impression materials stabilised by a tray did not differ significantly from waxes and record rims. Therefore the stabilised impression materials are an alternative that also gives additional advantages like reduction of appointments as well as superior accuracy. ${ }^{14}$

1 Freilich $\mathrm{M}$, Altieri J, Wahle J. Principles for selecting interocclusal records for articulation of dentate and partially dentate casts. J Prosthet Dent 1992: 68: 361-367.

2 Müller J, Götz G, Hörz W, Kraft E. Study of the accuracy of different recording materials. J Prosthet Dent 1990; 63: 41-46.

3 Millstein $\mathrm{P}, \mathrm{Hsu}$ C. Differential accuracy of elastomeric recording materials and associated weight change. J Prosthet Dent 1994; 71: 400-403.

4 Warren K, Capp N. A review of principles and techniques for making interocclusal records for mounting working casts. Int J Prosthodont 1990; 3: 341-348.

5 Öckert-Eriksson G, Eriksson A, Lockowandt P, Eriksson O. Materials for interocclusal records and their ability to reproduce a 3-dimensional jaw relationship. Int J Prosthodont 2000; 13: 152-158.

6 Helkimo M. Prosthodontic treatment of partially edentulous patients. Various centric positions and methods of recording them. Zarb G A, Bergman B, Clayton JA, Mac Kay HF (eds.) pp171-187. Saint Louis: CV Mosby, 1978.

7 McKee J R. Comparing condylar position repeatability for standardized versus nonstandardized methods of achieving centric relation. J Prosthet Dent 1997; 77 : 280-284.

8 Watson C J, Rowlands P W, Thomas S, Huggett R, Bates J F. The reproducibility of recording centric jaw relation in the edentulous patient. Quintessence Int 1987; 1: 35-40.

9 Posselt U. Physiology of occlusion and rehabilitation. p 117. Oxford: Blackwell, 1968.

10 Eriksson A, Öckert-Eriksson G, Lockowandt P. Accuracy of irreversible hydrocolloids (alginates) for fixed prosthodontics. Eur J Oral Sci 1998; 106: 651-660.

11 Eriksson A, Öckert-Eriksson G, Lockowandt P, Lindén L-Å. Irreversible hydrocolloids for crown and bridge impressions. Dent Mater 1996; 12: 74-82.

12 Neter J, Wasserman W, Kutner M. Applied Linear Statistical Models. pp 725-730, 851859. Boston, MA: Irwin, 1990

13 Mericske-Stern R, Assal P, Mericske E, Burgin W. Occlusal force and oral tactile sensibility measured in partially edentulous patients with ITI implants. Int J Oral Maxillofac Implants 1995; 10:345-353.

14 Breeding L, Dixon D, Kinderknecht K. Accuracy of three interocclusal recording materials used to mount a working cast. J Prosthet Dent 1994; 71: 265-270. 